\title{
The Status of International Collaboration in Writing Specialised Articles on Water Pollution, Air Pollution and Solid Waste Management
}

Aram Tirgar

Social Determinants of Health Research Center, Health Research Institute, Babol University of Medical Sciences, Babol, Iran

Zahra Aghalari ( $\nabla$ z.aghalari@gmail.com )

Environment HealthEngineering, Student Research Committee ofPublic Health, Gonabad University of Medical Sciences, Gonabad, Iran(I.R.Iran)

https://orcid.org/0000-0002-9629-1433

Mika Sillanpää

Department of Civil and Environmental Engineering, Florida International University, Miami, FL, USA

\section{Data Article}

Keywords: Water Pollution, air pollution, solid waste management, environmental health, international collaborations

Posted Date: August 6th, 2020

DOI: https://doi.org/10.21203/rs.3.rs-52874/v1

License: (c) (1) This work is licensed under a Creative Commons Attribution 4.0 International License. Read Full License 


\section{Abstract}

\section{Background}

Conducting research and writing articles in the three specialised fields of environmental health, air pollution, water pollution and solid waste management through collaboration between Iranian and international researchers lead to information exchange, science advancement and environmental problem-solving. This study therefore aimed to determine the status of international collaboration in writing specialised articles on water and air pollution and solid waste management.

\section{Methods}

This descriptive cross-sectional study was conducted over twelve years (2008-2019) by reviewing all articles published in the fields of air pollution, water pollution and solid waste management in five specialised environmental health journals. All articles were downloaded after visiting the journal site. The full text of the articles was reviewed and articles that matched the purpose of the study were included in it. Data were collected using a researcher-made checklist. The information included in the checklist was the number of articles published and the status of the authors' participation in terms of number, gender, country and continent in each of the fields of water pollution, air pollution and solid waste management. Statistical analysis of data was performed using a T-test. VOS viewer software was used to visualise the data and chart the extent of the international authors' involvement with Iranian researchers from different continents and countries.

\section{Results}

A review of 1,679 articles in 135 editions of five specialised environmental health journals revealed that 883 of the articles were in the fields of water and air pollution and solid waste management and 123 of the articles were written by international researchers. The top continents concerning collaboration in writing articles with Iran were Asia, Africa and Europe, respectively, with 70, 22, and 19 articles. In all three fields, India had the highest scientific participation with Iran. The gender distribution of the authors in these 123 articles with the participation of international authors showed that of the 406 authors, $35.7 \%$ were female and $65.3 \%$ were male and, for articles with just Iranian authors, $28.6 \%$ were female and $72.4 \%$ were male. The T-test for comparing the mean number of male and female authors in each article with and without the participation of international researchers showed no significant difference.

\section{Conclusions}

Based on their findings and comparisons with other research on the amount of scientific contributions by international researchers in other countries, it was found that the extent of international participation in the compilation of articles on water pollution, air pollution and solid waste management was large. However, given the low proportion of European and American collaboration in articles, it seems necessary to adopt ways to attract more researchers from advanced countries in the fields of air pollution, water pollution and solid waste management.

\section{Background}

The field of environmental health is one of the most valuable branches of medical science taught or researched at many prestigious universities around the world (1). The three specialised fields of environmental health are water pollution, air pollution and solid waste management, each of which has a great impact on the creation or prevention of diseases and the promotion of human health. For example, water pollution through various pollutants such as pathogens, organic and synthetic compounds, chemicals and minerals, plant materials, radioactive substances, waste, oil and sediment have adverse effects on human health, animal life and the environment (2-3). According to the United States Environmental Protection Agency (EPA), about one-third of the world's water resources are polluted. In this report, pollution is a hazard that damages the chemical, physical and even aesthetic properties of water (4). In recent years, air pollution has also become a major environmental concern in all countries due to its detrimental effects on health, the economy and the environment (5-6). According to World Health Organization estimates, 800,000 people die prematurely each year from cardiovascular and respiratory diseases and lung cancer due to air pollution worldwide (7). Poor waste management can also be attributed to the inappropriate handling and unhealthy disposal of various municipal, industrial, commercial and sanitary wastes, which cause water, soil and air pollution (8). It can endanger human health and cause, for example, respiratory diseases or diarrhoea (9)

According to the above, conducting research related to the three main fields of environmental health, namely water pollution, air pollution and solid waste management is essential to the protection of human health and environmental resources (10-11).

Constantly assessing water pollution, air pollution and solid waste management in different communities and publishing the findings in the form of scientific articles and reports lead to the production of a set of accurate information to identify epidemics and environmental problems and to provide the right solutions (12).

A wide range of scientific topics in the field of water pollution (such as contamination of ground- and surface water sources, turbidity, chlorine, taste and odour), air pollution (such as indoor pollution, outdoor pollution, ozone and carbon monoxide pollution as global problems), solid waste management (such as leachate, landfills, heavy metals) is persuading environmental health researchers to improve the quality of science and find practical and constructive solutions to environmental problems through scientific collaboration with international and other researchers.

Recently, national and international scientific collaboration has increased, and prestigious scientific journals prefer to publish articles that are the result of the efforts of more researchers, especially authors from several countries (13). In Iran and in the fields of environmental health, it is expected that research and articles will be conducted with the participation of an increasing number of international experts and researchers as is taking place in other countries and in 
medical science. The study by Royle et al. (2007) about the examination of trends in Chinese co-authorship showed that about half of these researchers' outputs came from international scientific collaboration (14). In a study by Hayati et al. (2010), which examined the collaboration of Iranian researchers with other countries in publications indexed in the Science Citation Database from 1998 to 2007, it was found that Iranians collaborated with 115 countries worldwide (15).

Due to the importance of international scientific collaboration by researchers in the scientific production of the specialised fields of environmental health, this study aimed to determine the status of international collaboration in writing specialised articles on water and air pollution and solid waste management.

\section{Methods}

\section{Research design}

This descriptive and cross-sectional study was conducted retrospectively over a twelve years period (2008-2019) on articles published in specialised environmental health journals. The inclusion criteria were for the journal to be a scientific-research or specialised journal, to have 'environmental health' in the title, to have at least four issues per year, and to have published articles for at least three consecutive years. According to these criteria, three Persian-language journals and two English-language journals were evaluated as described in Table 1.

Table 1

Frequency of articles on water and air pollution and solid waste management in Iranian environmental hea

\begin{tabular}{|c|c|c|c|c|c|c|c|c|c|c|c|c|c|}
\hline \multirow{3}{*}{$\begin{array}{l}\text { Publication } \\
\text { Year }\end{array}$} & \multicolumn{13}{|l|}{ Journals } \\
\hline & \multicolumn{4}{|l|}{ IJHE } & \multicolumn{4}{|l|}{ JEHE } & \multicolumn{4}{|l|}{ JRHE } & \multirow{2}{*}{$\begin{array}{l}\text { JEHSE } \\
\text { Numbe } \\
\text { of } \\
\text { Article }\end{array}$} \\
\hline & $\begin{array}{l}\text { Number } \\
\text { of } \\
\text { Article }\end{array}$ & $\begin{array}{l}\text { Water } \\
\text { Related } \\
\text { Article }\end{array}$ & $\begin{array}{l}\text { Air } \\
\text { Related } \\
\text { Article }\end{array}$ & $\begin{array}{l}\text { Solid } \\
\text { Waste } \\
\text { Related } \\
\text { Article }\end{array}$ & $\begin{array}{l}\text { Number } \\
\text { of } \\
\text { Article }\end{array}$ & $\begin{array}{l}\text { Water } \\
\text { Related } \\
\text { Article }\end{array}$ & $\begin{array}{l}\text { Air } \\
\text { Related } \\
\text { Article }\end{array}$ & $\begin{array}{l}\text { Solid } \\
\text { Waste } \\
\text { Related } \\
\text { Article }\end{array}$ & $\begin{array}{l}\text { Number } \\
\text { of } \\
\text { Article }\end{array}$ & $\begin{array}{l}\text { Water } \\
\text { Related } \\
\text { Article }\end{array}$ & $\begin{array}{l}\text { Air } \\
\text { Related } \\
\text { Article }\end{array}$ & $\begin{array}{l}\text { Solid } \\
\text { Waste } \\
\text { Related } \\
\text { Article }\end{array}$ & \\
\hline 2008 & 16 & 7 & 2 & 3 & - & - & - & - & - & - & - & - & 41 \\
\hline 2009 & 32 & 8 & 2 & 7 & - & - & - & - & - & - & - & - & 42 \\
\hline 2010 & 47 & 20 & 3 & 2 & - & - & - & - & - & - & - & - & 42 \\
\hline 2011 & 48 & 14 & 4 & 11 & - & - & - & - & - & - & - & - & 45 \\
\hline 2012 & 47 & 23 & 3 & 1 & - & - & - & - & - & - & - & - & 38 \\
\hline 2013 & 48 & 13 & 13 & 4 & 16 & 7 & 1 & - & - & - & - & - & 31 \\
\hline 2014 & 48 & 17 & 3 & 0 & 32 & 18 & 1 & 3 & - & - & - & - & 152 \\
\hline 2015 & 48 & 14 & 8 & 5 & 32 & 13 & 7 & 5 & 32 & 11 & 2 & 7 & 86 \\
\hline 2016 & 48 & 12 & 10 & 7 & 32 & 14 & 2 & 1 & 31 & 10 & 5 & 7 & 20 \\
\hline 2017 & 48 & 18 & 8 & 3 & 24 & 13 & 4 & 0 & 21 & 7 & 5 & 2 & 25 \\
\hline 2018 & 48 & 11 & 7 & 5 & 32 & 10 & 2 & 6 & 28 & 11 & 2 & 4 & 32 \\
\hline 2019 & 36 & 7 & 4 & 4 & 32 & 5 & 4 & 3 & 21 & 7 & 4 & 3 & 109 \\
\hline Total & 514 & 164 & 67 & 52 & 200 & 80 & 21 & 18 & 133 & 46 & 18 & 23 & 663 \\
\hline
\end{tabular}

The inclusion criteria were for the article to address one of the issues of air pollution, water pollution or solid waste management and to be available in full text. Articles were excluded if only their abstracts were available.

\section{Data Collection}

All articles were downloaded after visiting the dedicated journal sites. The full text of the articles was reviewed. Articles that matched the purpose of the study were included in this study. The data were collected through a researcher-made checklist and in accordance with the scientometrics method (16-17). The checklist collected information on the status of the authors' participation in terms of number, gender, country and continent in the fields of water and air pollution and solid waste management.

Included in the study are collaborations by Iranian authors with authors and researchers from other countries or the presence of at least one author with nonIranian affiliation in articles in the fields of water and air pollution and solid waste management.

\section{Statistical analysis}

The collected data were entered into Excel software. They were processed using descriptive and inferential statistical indices such as dispersion indices, centre tendency and the T-test. 
VOS viewer software was used to visualise the data and to show the extent of the researchers' involvement with different continents and with Iran. This software helps researchers visualise the co-authoring networks of authors from different countries. For example, this software enables the display of data density in different colours, clustering and scattering at different geographical locations (18).

\section{Results}

\section{Information on journals and articles}

In five environmental health journals, 1,679 articles were published in 135 issues over twelve years. Of the 883 articles, 529 (30.3\%) were in the field of water pollution, $196(11.22 \%)$ air pollution and $158(9.1 \%)$ solid waste management (Table 1).

\section{International Collaboration In The Compilation Of Articles}

Of the 883 articles in the three fields of water and air pollution and solid waste management, 123 articles (13.9\%) were written by researchers from other countries, 67 (54.57\%) of which were related to water pollution, 29 articles (23.53\%) were on air pollution and 27 articles (21.9\%) on waste management (Fig. 1).

\section{Number And Gender Of Authors}

The 883 articles in the three fields of water and air pollution and solid waste management were written by 3,145 researchers, and 760 of the articles were exclusively written by 2,739 Iranian researchers, the minimum and maximum number of authors ranging from 1 to 18 (3.75 \pm 1.5 ). In the 123 articles published with the participation of non-Iranian researchers, the number of non-Iranian collaborations was between 1 and 7 and the average number of authors with nonIranian researchers $(3.5 \pm 1.57)$.

The gender distribution of the authors in the 123 articles with international collaboration showed that of the 406 authors, 145 were female (35.7\%) and 261 (65.3\%) male. The gender distribution of articles with purely Iranian authors was 1,984 (72.4\%) male and 755 (28.6\%) female.

The minimum and maximum number of male authors in collaborative articles varied between 0 and 7 authors (2.9 \pm 1.4$)$. The minimum and maximum number of female authors in collaborative articles varied between 0 and 3 authors $(0.53 \pm 0.71)$. The minimum and maximum number of male authors in noncontributing articles was 0 to 11 authors $(3.1 \pm 1.02)$ and the minimum and maximum number of female authors in non-contributing articles was 0 to 5 authors $(1.8 \pm 0.57)$. The T-test for comparing the mean number of male and female authors in each article with and without the collaboration of international researchers showed no significant difference.

The separation of articles based on the three fields of water and air pollution and solid waste management showed water pollution to have the highest number of international collaborations in writing scientific articles with a frequency of 235 authors. Of the total of 3,145 Iranian and international authors who participated in the writing of the 883 articles in the three fields of water and air pollution and solid waste management, 406 (12.9\%) participated in the writing of 123 joint articles (Table 2).

Table 2

Frequency of authors by gender in articles with and without international collaborations 2008-2019

\begin{tabular}{|c|c|c|c|c|c|c|}
\hline \multirow{2}{*}{$\begin{array}{l}\text { Fields of } \\
\text { environmental } \\
\text { health }\end{array}$} & \multicolumn{2}{|l|}{ Male } & \multicolumn{2}{|l|}{ Female } & \multicolumn{2}{|l|}{ Total } \\
\hline & $\begin{array}{l}\text { Articles with } \\
\text { international } \\
\text { collaboration }\end{array}$ & $\begin{array}{l}\text { Articles without } \\
\text { international } \\
\text { collaboration }\end{array}$ & $\begin{array}{l}\text { Articles with } \\
\text { international } \\
\text { collaboration }\end{array}$ & $\begin{array}{l}\text { Articles without } \\
\text { international } \\
\text { collaboration }\end{array}$ & $\begin{array}{l}\text { Articles with } \\
\text { intermational } \\
\text { collaboration }\end{array}$ & $\begin{array}{l}\text { Articles withou } \\
\text { international } \\
\text { collaboration }\end{array}$ \\
\hline $\begin{array}{l}\text { Water } \\
\text { pollution }\end{array}$ & 174 & 1,206 & 88 & 426 & 235 & 1,632 \\
\hline Air pollution & 70 & 417 & 23 & 174 & 93 & 591 \\
\hline $\begin{array}{l}\text { Solid waste } \\
\text { management }\end{array}$ & 44 & 361 & 34 & 155 & 78 & 516 \\
\hline Total & 261 & 1,984 & 145 & 755 & 406 & 2,739 \\
\hline
\end{tabular}

\section{Iranian Researchers' Collaboration With International Researchers}

Among the 529 articles related to water pollution, 67 collaborative articles were written by 235 researchers from 20 countries. The largest contributors to research on water pollution were from the continent of Asia with 42, then came Africa and Europe with 14 and 11, respectively.

The highest collaborative rate in writing about water pollution came from India with 38 researchers collaborating on 12 articles, 20 Malaysian researchers collaborated on 10 articles and 17 Chinese on 7 articles.

Of the 196 articles related to air pollution, 93 authors contributed to 29 international articles. Of these 93 authors, 33 researchers were from 5 Asian countries and contributed to 15 articles. The highest number of collaborations in the writing of air pollution articles were from Indian researchers ( 5 articles and 12 
authors), Turkey (4 articles and 6 authors) and Taiwan (3 articles and 9 authors).

Of the 158 articles on solid waste management, 27 were written with the participation of 78 authors from three continents, most of whom were from Asia with 18 articles. The evaluation of researcher collaboration from the perspective of countries showed that, despite 11 countries collaborating in waste management research, Indian researchers (with 16 articles and 35 authors), Egyptian researchers ( 2 articles and 8 researchers), and Chinese researchers ( 2 articles and 6 researchers) were the most collaborative with Iran.

VOSviewer software was used to map the co-authoring network of Iranian researchers with international researchers across continents and countries in all specialised articles on the three fields of environmental health issues (water and air pollution and solid waste management). Based on this software, a network was drawn in which the size of each node represents the number of articles shared by each country and continent with Iran, and the diameter of the link between the two nodes is proportional to the number of co-authored articles. Because of the collaboration of countries with Iran in this study, Iran was placed at the centre of the nodes with the largest number of articles. In this map, the continents and countries most closely associated with Iranian writers were geographically closer to Iran, i.e. Asia, Africa, and Europe (Fig. 2). In total, 27 countries collaborated with Iran in the writing of 123 articles, and the highest number of collaborations were from India, China, Malaysia and Turkey with 25, 15, 14 and 9 articles, respectively (Fig. 2).

A survey of 123 articles written by Iranian and international authors in the three fields of water and air pollution and solid waste management showed that the largest number of researchers were from India and China with 64 and 47, respectively. In total, 27 countries from 5 continents were involved in writing articles with Iran (Fig. 3). Among the articles reviewed, five were written in collaboration with more than two countries and four were published by researchers from three countries: Iran, Malaysia and Japan; Iran, South Korea and India; Iran, Ethiopia and Mexico; Iran, Egypt, Spain. One article was written between four countries: Iran, South Korea, China and India. The study of the authors' distribution by continent showed that of 406 authors, 284 were from 11 countries in Asia. Also, the largest number of 70 articles came from Asia. Researchers from Africa, Europe, the United States and Oceania published 22, 19,11 and 1 articles with Iranian researchers, respectively (Fig. 3).

\section{Discussion}

The findings on the status of scientific collaboration in water and air pollution and solid waste management articles over a decade showed that, of the 883 articles published in three fields, 123 articles (13.9\%) were written with the collaboration of non-Iranian researchers. A study by Royle et al. which aimed to determine the amount of scientific participation in more than 35,000 Chinese researchers' articles in Elsevier publications during 2004 found that about $20 \%$ of the Chinese researchers' output came from international collaboration (14). A study by Zhang et al. in China, a survey of health management research in ISI journals from 1999 to 2011, found that the status of collaboration among Chinese researchers with authors from other countries was about 13\% (19). A study by Zyoud et al. about Arab countries' research publications on pharmaceutical wastewater on the Scopus database showed that international collaboration in wastewater scientific publications between Arab and European countries was $30.2 \%$ (20). This present comparison of international collaboration in scientific production in the fields of water and air pollution and solid waste management in Iranian publications compared to other Asian studies showed, that despite the acceptable status of Iran's scientific status, the level of scientific collaboration is unsatisfactory, and expanding Iran's scientific cooperation with other countries is essential.

The continental categorisation of articles by Iranian researchers and other countries showed that the largest number of articles (56.9\%) belonged to 11 Asian countries, with the participation of 284 researchers. The study by Tirgar et al. (2019) showed that the status of the international collaboration of Iranian researchers with Asian researchers in compiling environmental health engineering articles was $63.5 \%$ higher than that of other continents (21). One of the possible reasons for the high participation of Asian researchers in the dissemination of scientific articles in this field of study in Iran is that Asia is the most populous continent in the world where environmental pollution, including air and water pollution, are widespread and will affect human health for a long time to come. For example, China is one of the Asia's most pressing environmental challenges today. Air pollution is the main environmental problem causing cardiopulmonary diseases in China and Thailand. In South Korea, the health of children and the elderly is also at risk due to the neglect of environmental health (22). Another reason could be the proximity of Asian countries. In a study by Royle et al. (2007), one of the reasons for researcher participation in writing scientific articles is the geographical proximity of countries (14). Many Asian countries have also had friendly relations and are politically close and broadly involved, which may be one of the reasons for the high level of participation of Asian researchers in this study.

In the present study, the rate of participation of European and American researchers as advanced countries was 19 (15.4\%) and 11 (8.9\%), respectively. A study by Soteriades et al. aimed at analysing articles from 1995 to 2003 in the ISI database in various environmental, occupational and public health fields showed that American countries in the fields mentioned produced science with $60 \%$ of articles published and then European countries came in second place (23). According to this finding, it seems that, regardless of the extent of international participation, the choice of country and continent by scientific partners is of paramount importance. For this reason, it is better to develop partnerships with developed countries, including American and European countries, as international partnerships develop in scientific and research activities. It should be noted, however, that the limited involvement of Iranian researchers with European and American countries can be due to political and even economic issues, as noted in the study of Tabatabaei-Malazy et al. In the field of herbal medicine, the trend of the publication of articles increased from 1997 to 2014, but since 2014, sanctions against Iran have reduced the production of articles (24).

The findings on the collaboration of researchers from other countries with Iranian researchers showed that a total of 27 countries participated in writing 123 articles with Iran. Overall, in all three fields of water and air pollution and solid waste management, India had more research collaboration with Iran. The results of the study by Zyoud et al. about the medical journals of Arab countries in the ICM journal database were similar to those of the present study due to greater international cooperation in writing articles on the Asian continent with India (25). This could be attributable to studies by Asian researchers in India or the proximity of India to other Asian countries. 
According to the findings of this study, the gender distribution of the authors in the 123 articles with the participation of international authors showed that $35.7 \%$ were female and $65.3 \%$ male. West et al. (2013), in a study of scientific articles published in the JSTOR corpus database aimed at sexually identifying authors of scientific articles, reported that $21.9 \%$ of the authors were female (26). Amrein's research on the top 60 medical journals in the ISI database showed that the editorial boards of medical journals contained only $15.9 \%$ women (27). In line with the results of these studies, the results indicate the acceptable contribution of Iranian female researchers in conducting research, including health research, in Iran.

One of the strengths of this study is the use of scientometric and citation analysis methods to evaluate the scientific production status of three specialised environmental health fields (water pollution, air pollution and solid waste management), which have not received much attention in health research. Also, the strengths of this study are the analysis of a long period of time (a decade), the review of articles in all specialised environmental health journals and the use of advanced VOSviewer software. The limitations of this study include failure to review articles on water pollution, air pollution and solid waste management in other specialised health journals.

\section{Conclusion}

Based on their findings and comparisons with other studies on the amount of scientific contributions by international researchers in other countries, it was found that the extent of international participation in the compilation of articles on water pollution, air pollution and solid waste management was at a good level. However, given the low proportion of European and American collaborations in articles, it seems necessary to adopt ways to attract more researchers from advanced countries in the fields of air pollution, water pollution and solid waste management.

\section{Abbreviations}

\section{EHEMJ}

Environmental Health Engineering and Management Journal

IJHE

Iranian Journal of Health and Environment

JEHE

Journal of Environmental Health Engineering

JEHSE

Journal of Environmental Health Science and Engineering

JREH

Journal of Research in Environmental Health

ICMJE

International Committee of Medical Journal Editors

WAME

World Association of Medical Editors

\section{Declarations}

\section{Availability of data and materials}

Restrictions apply to the data availability, which were used under license for the current study, and thus are not publicly available. However, data are available from the authors upon reasonable request and with the study participants' permission.

\section{Acknowledgements}

The cooperation of all the professors, students and researchers whose articles were published in journals as a source for this research, and that of the Deputy of Research and Technology of Gonabad University of Medical Sciences are highly appreciated. This study was registered and approved by the Code of Ethics (IR.GMU.REC.1396.110).

\section{Consent to publication}

Not applicable

\section{Funding}

This research benefited from the support of the Deputy of Research and Technology of Gonabad University of Medical Sciences. The funders had no role in the study design, data collection and analysis, decision to publish, or preparation of the manuscript.

\section{Author information}

\section{Affiliations}

Social Determinants of Health Research Center, Health Research Institute, Babol University of Medical Sciences, Babol, Iran, Email: a.tirgar@mubabol.ac.ir 
Corresponding Author, Department of Environmental Health Engineering, Faculty of Health, Gonabad University of Medical Sciences, Gonabad, Iran' Email: z.aghalari@gmail.com

2. Department of Civil and Environmental Engineering, Florida International University, Miami, FL, USA, Email: mikaesillanpaa@gmail.com

\section{Contributions}

ZA conceived the study, made final decisions on the inclusion of journal articles and extracted data from them, and wrote and revised the manuscript. AT designed the study, made final decisions on the inclusion of journal articles and extracted data from them, and wrote and revised the manuscript.MS wrote and revised the manuscript and made final decisions on the inclusion of journal articles.

\section{Corresponding author}

Correspondence to Zahra Aghalari

\section{Ethics declarations}

\section{Ethics approval and consent to participate}

This research benefited from the support of the Deputy of Research and Technology of Gonabad University of Medical Sciences. This study was approved and registered by the Code of Ethics (IR.GMU.REC.1396.110).

\section{Competing interests}

The authors declare that they have no competing interests.

\section{References}

1. LiuEmail HY, BartonovaA PM, Smolders R, Skjetne E, Dusinska M (2012) Approaches to Integrated monitoring for environmental health impact assessment. Environ Health 11:88. https://doi.org/10.1186/1476-069X-11-88

2. Sasikaran S, Sritharan K, Balakumar S, Arasaratnam V (2012) Physical, chemical and microbial analysis of bottled drinking water. Ceylon Med J 57:111116

3. AL-Dulaimi GA, Younes MK Assessment of Potable Water Quality in Baghdad City, Iraq Air Soil Water Research. $2017 ; 10$. https://doi.org/10.1177/1178622117733441

4. 10.18869/acadpub.jehe.4.2.174 Komasi M, Sharghi S. Surface Water Quality Assessment and Prioritize the Factors Pollute This Water Using Topsis Fuzzy Hierarchical Analysis. jehe. 2017; 4 (2):174-184. https://doi.org/ 10.18869/acadpub.jehe.4.2.174. (Abstract in English)

5. Jafarian S, Aghalari Z, Najar M (2018) Evaluating the Knowledge and Attitude of Air Pollution Control in Tehran from the Elderly and Pregnant Women2017. J Saf Promot Inj Prev 6(2):73-80.(persian)

6. Najafpoor AA, Hosseinzadeh A, Allahyari S, Javid AB, Esmaily H (2014) Modeling of CO and NOx produced by vehicles in Mashhad, 2012. Environmental Health Engineering Management Journal 1(1):45-49

7. Anderson JO, Thundiyil JG, Stolbach A (2012) Clearing the air: a review of the effects of particulate matter air pollution on human health. J Med Toxicol 8(2):166-175. doi:10.1007/s13181-011-0203-1

8. Hashemi M, Khanjani N, Saber M, Fard NK (2012) Health literacy of Kerman Medical University, school of public health students about recycling solid waste. J Educ Health Promot 1:41

9. Mukama T, Ndejjo R, Musoke D et al. Practices, Concerns, and Willingness to Participate in Solid Waste Management in Two Urban Slums in Central Uganda. J Environ Public Health. 2016; 6830163

10. Ikonen J, Pitkänen T, Miettinen IT (2013) Suitability of optical, physical and chemical measurements for detection of changes in bacterial drinking water quality. Int J Environ Res Public Health 10(11):5349-5363. https://doi.org/10.3390/ijerph10115349

11. Fisher MB, Williams AR, Jalloh MF, Saquee G, Bain RE, Bartram JK (2015) Microbiological and Chemical Quality of Packaged Sachet Water and Household Stored Drinking Water in Freetown, Sierra Leone. PLoS One 10(7):e0131772. https://doi.org/10.1371/journal.pone.0131772

12. Yan CA, Zhang W, Zhang Z, Liu Y, Deng C, Nie N (2015) Assessment of water quality and identification of polluted risky regions based on field observations \& GIS in the Honghe River watershed, China. PLoS One 10(3):e0119130. https://doi.org/10.1371/journal.pone.0119130

13. Rahimi M, Fatahi R. Assessment and production of information: regarding concepts and common pattern in current science production. Faslnemeye Ketab. 2007;71

14. Royle J, Louisa C, Dorothy W, Paul E (2007) Publishing in International Journals: An Examination of Trends in Chinese Co-authorship. Scientometrics 71(1):59-86

15. Hayati Z, Didegah F (2010) International scientific collaboration among Iranian researchers during 1998-2007. Library Hi Tech 28(3):433-446

16. Tirgar A, Abolghasemi MB, Yaminfirooz M. Citation analysis of graduate dental thesis references: Before and after an intervention. Future of Medical Education Journal. 2013;3(1):2-7 
17. Aghalari Z, Tirgar A (2017) Topics of Disasters in Scientific Outputs of Medical Sciences: A Cross-Sectional Study. Health in Emergencies Disasters Quarterly 2(2):47-52

18. Van Eck NJ, Waltman L. VOSviewer: A computer program for bibliometric mapping. In Larsen, B. and Leta, J. editors, Proceedings of the 12th International Conference on Scientometrics and Informetrics. 2009; 886-897

19. Zhang C, Yu Q, Fan Q, Duan Z (2013) Research Collaboration in Health Management Research Communities. BMC Med Inform Decis Mak $13: 52$

20. Zyoud SH, Zyoud SH, Al-Jabi SW, Sweileh WM, Awang R (2016) Contribution of Arab countries to pharmaceutical wastewater literature: a bibliometric and comparative analysis of research output. Ann Occup Environ Med 28:1-12

21. Tirgar A, Sajjadi SA, Aghalari Z (2019) The status of international collaborations in compilation of Iranian scientific articles on environmental health engineering. Globalization Health 15(17):1-9

22. ChoiEmail K, Paek D, Wu T, Chan CC, Onchang R, Padungtod C, Koizumi A (2012) Asian forum on environmental health policy: challenges and perspectives of environmental health problems in the region in the next 30 years. Environ Health Prev Med 17:269

23. Soteriades ES, Falagas ME (2006) A bibliometric analysis in the fields of preventive medicine, occupational and environmental medicine, epidemiology, and public health. BMC Public Health 6:301

24. Tabatabaei-Malazy O, Ramezani A, Atlasi R, Larijani B, Abdollahi M (2016) Scientometric study of academic publications on antioxidative herbal medicines in type 2 diabetes mellitus. Journal of Diabetes Metabolic Disorders 15:48

25. Zyoud SH, Al-Jabi SW, Sweileh WM (2015) Scientific publications from Arab world in leading journals of Integrative and Complementary Medicine: a bibliometric analysis. BMC Complement Altern Med 15:308. doi:10.1186/s12906-015-0840-z

26. West JD, Jacquet J, King MM, Correll SJ, Bergstrom CT (2013) The role of gender in scholarly authorship. PLoS One 8(7):e66212. doi:10.1371/journal.pone.0066212

27. Amrein K, Langmann A, Fahrleitner-Pammer A, Pieber TR, Zollner-Schwetz I (2011) Women underrepresented on editorial boards of 60 major medical journals. Gend Med 8:378-388. https://doi.org/10.1016/j.genm.2011.10.007

\section{Figures}

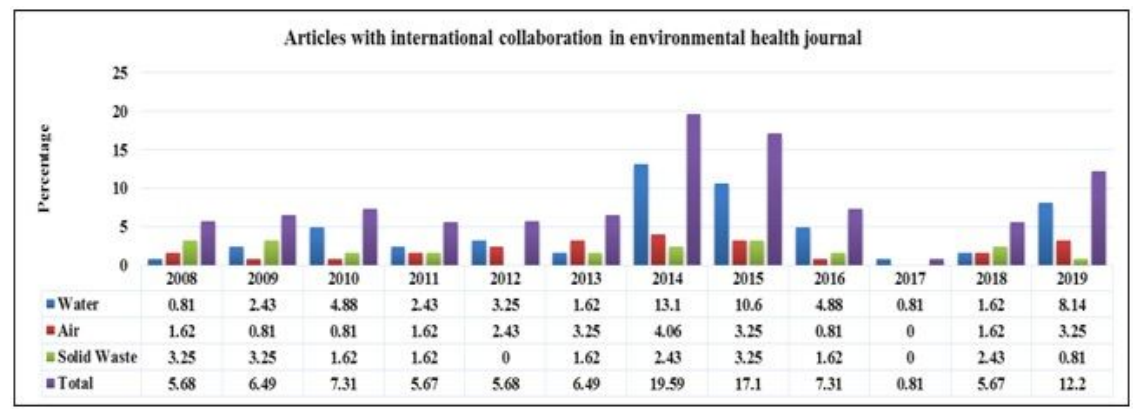

\section{Figure 1}

Frequency of articles published in the fields of water and air pollution and solid waste management with the contribution of international researchers (20082019)

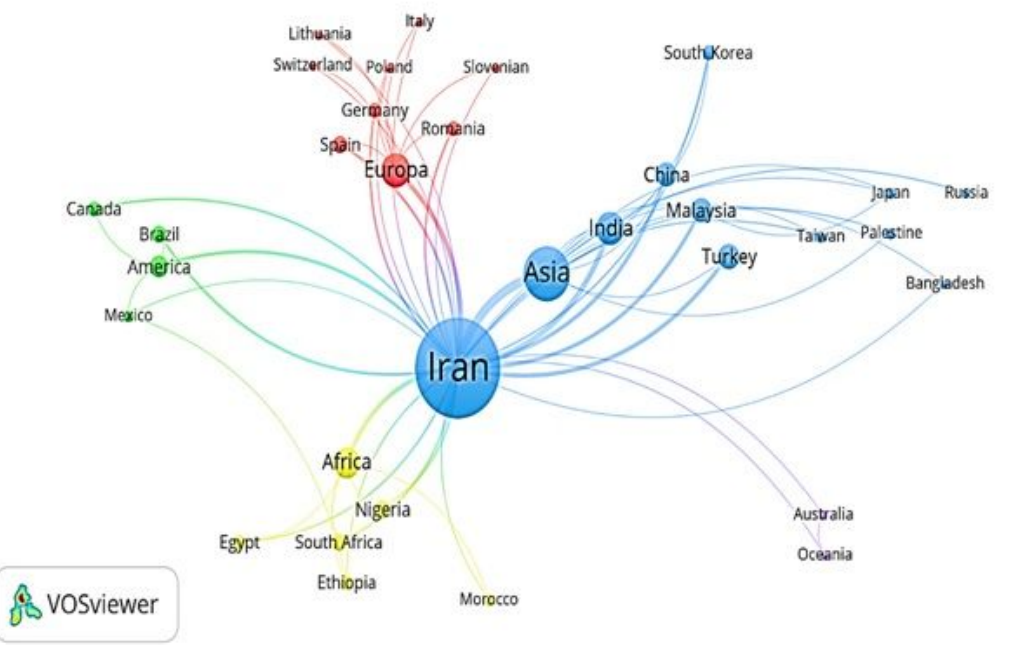

Figure 2 
Authors' collaboration network for articles on water and air pollution and solid waste management by continents and countries $2008-2019$

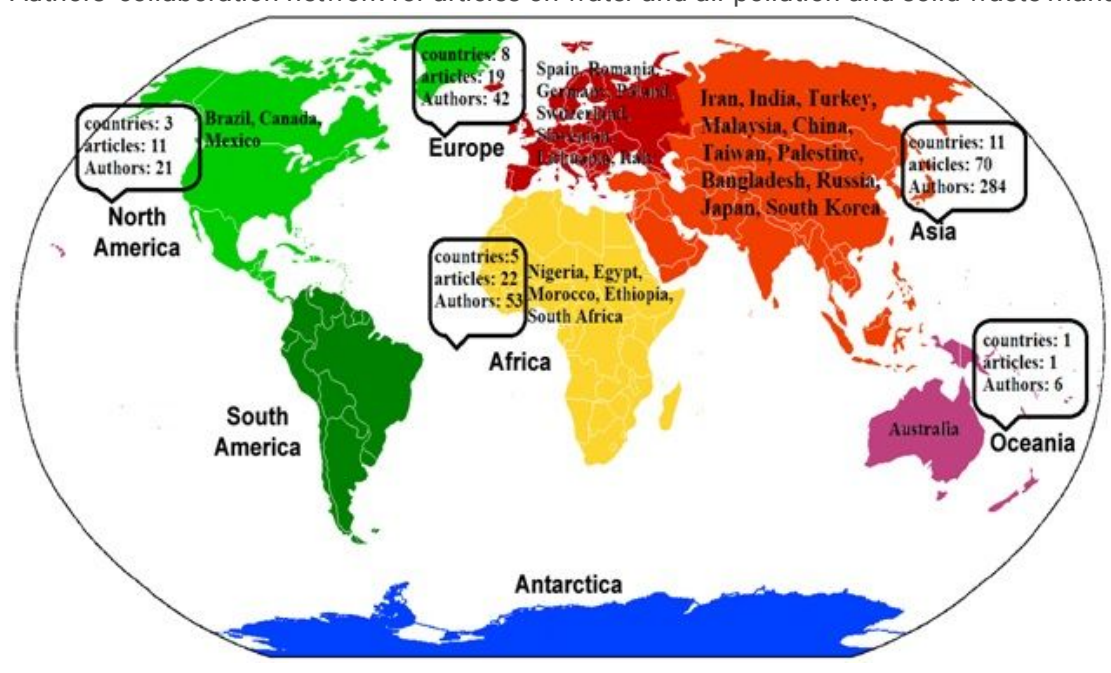

Figure 3

Global distribution of authors of articles written by international researchers in the fields of water and air pollution and solid waste management by country and continent (2008-2019). Note: The designations employed and the presentation of the material on this map do not imply the expression of any opinion whatsoever on the part of Research Square concerning the legal status of any country, territory, city or area or of its authorities, or concerning the delimitation of its frontiers or boundaries. This map has been provided by the authors.

\section{Supplementary Files}

This is a list of supplementary files associated with this preprint. Click to download.

- Additionalinformation.docx 